\title{
Marginal staining of ultra-thin ceramic veneers
}

\author{
Renata Ragagnin Zago ${ }^{1}$ iD, Luciana Abitante \\ Swarowsky $^{1}$ (iD, Gabriela Simões Teixeira ${ }^{1}$ (iD, \\ Marcela Marquezan ${ }^{3}$ iD, Alexandre Henrique \\ Susin $^{2}$ (ID), Letícia Brandão Durand ${ }^{2, *}$ (iD
}

${ }^{1}$ Graduate Program of the Federal University of Santa Maria, Santa Maria, RS, Brazil

${ }^{2}$ Department of Restorative Dentistry, Federal University of Santa Maria, Santa Maria, RS, Brazil

${ }^{3}$ Clinical Practice, Federal University of Santa Maria, Santa Maria, RS, Brazil
Corresponding author: Letícia Brandão Durand Department of Restorative Dentistry, Federal University of Santa Maria, Santa Maria, RS, Brazil Email: leticia_durand@yahoo.com

Received: February 27, 2020

Accepted: July 30, 2020
The pigmentation of the resin cement at the tooth/ceramic interface compromises the esthetic and longevity of ultra-thin ceramic veneers. Aim: The aim of this study was to evaluate marginal staining of ultra-thin ceramic veneers cemented to intact enamel (non-prepared) and prepared enamel. Methods: Thirty-two (32) permanent central incisors were selected and randomly divided into two groups: intact enamel (IE) and prepared enamel (PE). The ceramic veneers of PE group were bonded to the prepared enamel and the ceramic veneers of IE group were cemented directly onto the intact enamel, with no preparation. Both preparation and cementation were standardized and performed by a single operator. Each group was subdivided into two subgroups $(n=8)$ with different immersion media - coffee and water. After an immersion period of 10 days, stereomicroscope images were made at 20X magnification of the mesial, distal, cervical and incisal surface of each specimen. Three blinded, trained and calibrated examiners evaluated the images of the resin cement interface of each surface. The data were subjected to KruskalWallis and MannWhitney statistical analysis. Immersion media and enamel preparation influenced the marginal staining of the tooth/ceramic interface. Results: When immersed in coffee, prepared interfaces presented greater marginal staining than unprepared interfaces. When immersed in water, there was no statistically significant difference between the groups. Conclusion: The cementation of ultra-thin ceramic veneers onto intact enamel is associated with less marginal staining and, consequently, improved esthetics.

Keywords: Coffee. Dental enamel. Dental veneers. Esthetics. Staining and labeling. 


\section{Introduction}

Ultra-thin ceramic veneers have become one of the main treatment options for esthetic improvement of discolored, fractured, worn, malformed and misaligned anterior teeth ${ }^{1,2}$. The conservation of dental structures, high success rate and excellent esthetic outcomes contributed to expand the indications and increase the popularity of this procedure ${ }^{3,4}$. Despite the brittleness of the ceramic materials, resistance is improved due to the strong and stable bond produced when adhesive luting agents are used for cementation ${ }^{4,5}$. Thus, success is highly dependent on the quality of the adhesion on restricted enamel preparations, adequate ceramic surface treatments, and the use of proper luting agents ${ }^{6}$.

Luting agents provide a link between tooth and restoration. Various types of resin cements are indicated for the cementation of ceramic veneers, such as auto-, light-or dual-cured $^{7}$. Light cured resin cements are preferable because of the superior color stability due to the absence of tertiary amines. In addition, the presence of aliphatic amines reduces the oxidation susceptibility ${ }^{7,8}$ and the activation by light allows longer working time, as well, as optimization of the technique ${ }^{9}$.

Extensive enamel preparations with accidental dentine exposure are associated with reduced bond strength, increased microleakage ${ }^{10}$ and marginal defects ${ }^{11}$. Even when these circumstances do not result in absolute failure, they may complicate clinical outcomes $^{1,11}$. Contrarily, long-term survival rates are improved with conservative enamel preparations ${ }^{10}$. Moreover, when ceramic veneers are supported exclusively by enamel, the load-bearing capacity is increased, due to the similar modulus of elasticity between the structures ${ }^{12}$.

The trend toward the indication of conservative treatments, based on the principles of adhesion and minimally invasive dentistry, is widely encouraged. Prepless veneers are consolidated as an esthetic elective treatment. Conservative preparations are associated with increased esthetics and longevity ${ }^{13}$, nevertheless, the importance of the preservation of dental structures is unquestionable. The esthetic outcomes are important concerns and the high expectations may be compromised by marginal staining of the tooth/ceramic interface ${ }^{11}$. The above-listed arguments motivated this study, that aims to evaluate the marginal staining at the tooth/ceramic interface of ultra-thin veneers placed on intact and prepared enamel. The null hypothesis was that the enamel preparation would not affect the marginal staining of the tooth/ceramic interface of ultra-thin veneers.

\section{Materials and methods}

\section{Ethics}

The Research Ethics Committee of the participating institution (certificate number 7100, CAEE number 00564612.4.0000.5346) approved this study.

Thirty-two non-carious human mandibular incisors with a cervico-incisal length of $9.5 \mathrm{~mm}$ and a mesio-distal width of $5.5 \mathrm{~mm}( \pm 1 \mathrm{~mm})$ were selected from a tooth bank. 
The teeth were kept in $0.1 \%$ of thymol solution for two weeks for disinfection and then, stored in distilled water $\left(37^{\circ} \mathrm{C}\right)$, until specimen preparation.

\section{Specimen preparation}

The teeth were randomly assigned to two groups according to the different preparation alternatives: 1. intact enamel - with no preparation (IE) and 2. prepared enamel (PE). Half of the specimens of each group were immersed in water $(n=8)$ and the remaining half were immersed in a coffee solution $(n=8)$. The root of each tooth was embedded in acrylic resin blocks, $2 \mathrm{~mm}$ below the cement-enamel junction to facilitate specimen preparation.

\section{Enamel Preparation}

Dental enamel preparation was standardized and prepared by a trained operator. Initially, a silicon based impression was taken from the tooth crown (Virtual, Ivoclar Vivadent, Schaan, Liechtenstein). Afterwards, the impression was sectioned and used as a reference guide for enamel reduction. A $0.5 \mathrm{~mm}$-enamel reduction was performed with a diamond bur \#2135 (KG Sorensen, Cotia, SP, Brazil) (Figure 1A), using the window preparation technique. The cervical margin was placed $0.5 \mathrm{~mm}$ above the cement-enamel junction with a chamfer finishing line. In order to produce a smooth and well-finished surface, fine and extra fine grit diamond burs \# 2135 (KG Sorensen, Cotia, SP, Brazil) were used.

\section{Impression}

The impressions were taken by a thimble shaped tray (Figure 1B) through the single-step technique, which provides the simultaneous polymerization of the heavy and light-body impression material (Virtual, Ivoclar Vivadent, Schaan, Liechtenstein).
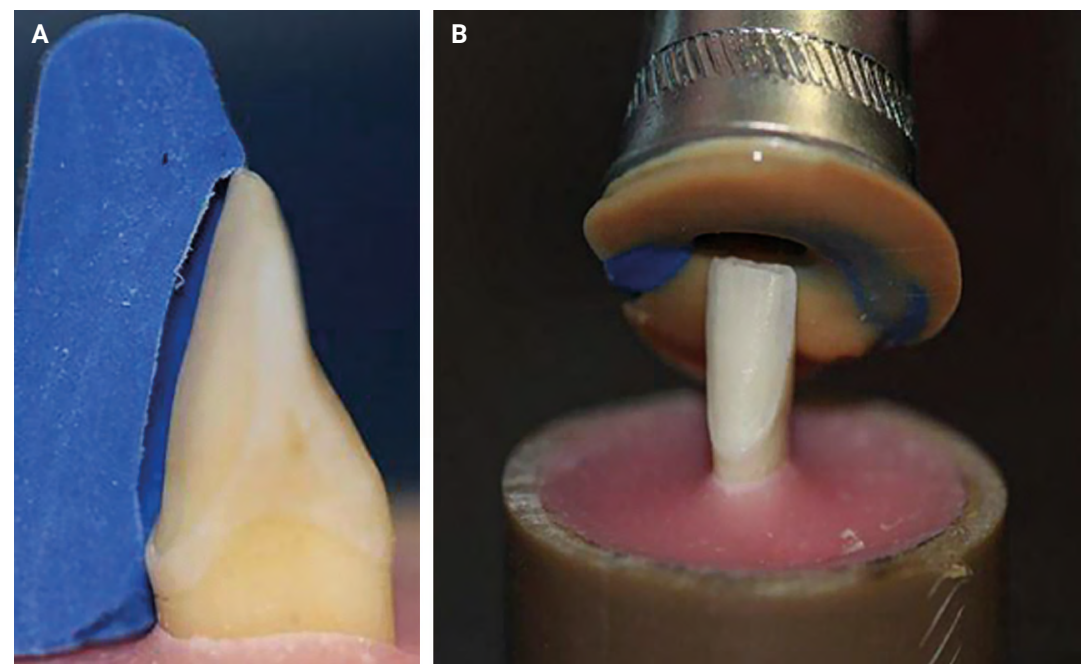

Figure 1. A) Enamel reduction using a silicon based impression as a reference guide. B) Impressions of specimens were taken using a thimble and through the single-step technique 


\section{Ceramic veneers}

Ceramic veneers were produced from a lithium disilicate glass ceramic (IPS e.max Press, Ivoclar Vivadent, Schaan, Liechtenstein), by one experienced dental technician, using the heat-pressed technique. The veneers produced for non-prepared enamel specimens were $0.3 \mathrm{~mm}$-thick, and for the prepared enamel specimens (PE) $0.5 \mathrm{~mm}$-thick.

\section{Bonding procedures and cementation}

The ceramic veneers were cemented to the tooth surfaces with light-curing resin cement (Variolink Veneer, Ivoclar Vivadent, Schaan, Liechtenstein), according to the manufacturer's instructions. Each specimen was light-cured for 150s, with a LED unit (Emmiter C, Schuster Eq. Odont Ltd, Santa Maria, RS, Brazil), with $800 \mathrm{~mW} / \mathrm{cm}^{2}$ of irradiance. The sequence of adhesive procedures is summarized in Figure 2 and the materials used in the study are described in Figure 3. After complete polymerization, the margins were polished with a silicon carbide finishing kit (KG Sorensen, Cotia, SP, Brazil), and washed in an ultrasonic bath (L100, Schuster Eq Odon. Ltd, Santa Maria, RS, Brazil) for 2 cycles of 480 s to remove residual particles from the resin cement or finishing points.

\section{Staining}

Half of the IE and PE specimens were stored in water at $37^{\circ} \mathrm{C}$, and the remaining specimens of each group were immersed in coffee. The coffee solution was prepared in a standardized manner, using $25 \mathrm{~g}$ of instant coffee powder (Nestlé, Caçapava, $\mathrm{SP}$, Brazil) and $250 \mathrm{ml}$ of water, for 10 days at $37^{\circ} \mathrm{C}$. The immersion solutions were replaced every $24 \mathrm{~h}$.

\section{Evaluation}

Marginal staining was assessed by observing digital images, similar to other studies reported in the literature ${ }^{5,14}$. Standardized images of the mesial, distal, incisal and cervical margins of each restoration were used for evaluation. The images were registered with a stereomicroscope (Carl Zeiss, Göttingen, Germany), using the AxioVision program at 20X magnification.

The examiners underwent a three-day training period, in which they received instructions on the evaluation procedure and became familiar with the scores. In addition, the examiners observed and rated 20 selected images of mesial, distal, cervical and incisal margins from specimens used in a previous pilot study. After seven days, the examiners evaluated the same images without receiving any initial instructions, and Kappa intra- and inter- examiners agreement was tested. Kappa values for intra-examiner agreement ranged from 0.73 to 0.93 , and inter-examiners agreement ranged from 0.77 to 1.0 .

Afterwards, the staining of the marginal finishing line was assessed for the 128 images according to Alfa, Bravo, Charlie and Delta scores (Figure 4). Each image was displayed on a full HD monitor in a random sequential order. The viewing distance was $50 \mathrm{~cm}$ and no time limit was set for each evaluation. 


\section{Statistical Analysis}

The scores were tabulated and analyzed with SPSS software (version 18.0; SPSS, Inc., Chicago, IL). The data were analyzed with the Kruskal-Wallis test, considering that it was not normally distributed. Subsequently, a Mann-Whitney U-test was used for pairwise comparisons among groups at a 0.05 level of significance $(p \leq 0.05)$.

\begin{tabular}{|c|c|c|c|}
\hline \multicolumn{2}{|c|}{ Tooth surface (sequence) } & \multicolumn{2}{|r|}{ Ceramic laminate veneers (sequence) } \\
\hline Step & Action & Step & Action \\
\hline 1 & Cleaning with pumice & 1 & $\begin{array}{l}10 \% \text { Hydrofluoric acid etching of inner side of the ceramic veneer } \\
\text { for } 20 \text { s }\end{array}$ \\
\hline 2 & $\begin{array}{l}\text { Acid etching for } 30 \text { s with } \\
37 \% \text { phosphoric acid gel }\end{array}$ & 2 & Rinsing with water spray for $60 \mathrm{~s}$ at $5 \mathrm{~cm}$ of distance \\
\hline 3 & $\begin{array}{l}\text { Rinsing with water for } 60 \mathrm{~s} \\
\text { at } 5 \mathrm{~cm} \text { of distance }\end{array}$ & 3 & Air drying for $10 \mathrm{~s}$ at $5 \mathrm{~cm}$ of distance \\
\hline 4 & $\begin{array}{l}\text { Air drying for } 5 \mathrm{~s} \text { at } 5 \mathrm{~cm} \text { of } \\
\text { distance }\end{array}$ & 4 & Silane coupling agent application - 60 s \\
\hline 5 & $\begin{array}{l}\text { Bonding agent application } \\
\text { and air thinning for } 10 \mathrm{~s} \text { at } \\
5 \mathrm{~cm} \text { of distance }\end{array}$ & 5 & $\begin{array}{l}\text { Bonding agent application and air thinning for } 10 \mathrm{~s} \text { at } \\
\qquad 5 \mathrm{~cm} \text { of distance }\end{array}$ \\
\hline 6 & Light-curing for $10 \mathrm{~s}$ & 6 & Light-curing for $10 \mathrm{~s}$ \\
\hline \multirow{6}{*}{7} & \multirow{6}{*}{$\begin{array}{l}\text { Cementation with light } \\
\text { curing resin cement }\end{array}$} & 7 & $\begin{array}{l}\text { Application of light-cure resin cement on the inner side of the } \\
\text { ceramic laminate veneer }\end{array}$ \\
\hline & & 8 & Positioning of the ceramic laminate veneer on the tooth \\
\hline & & 9 & Light-curing for 30 s \\
\hline & & 10 & Removal of excess resin cement \\
\hline & & 11 & Glycerin gel application in all interfaces \\
\hline & & 12 & Light-curing of each interface for 30 s \\
\hline
\end{tabular}

Figure 2. Sequence of adhesive procedures on tooth surfaces and ceramic veneers

\begin{tabular}{|c|c|c|c|}
\hline Product & Type & Chemical Composition & Manufacturer \\
\hline $\begin{array}{l}\text { Condac } \\
\text { Porcelana }\end{array}$ & Ceramic etching gel & $\begin{array}{l}\text { Low viscosity gel with } 10 \% \text { hydrofluoric acid, water, } \\
\text { thickening agent and colorants }\end{array}$ & \multirow{2}{*}{$\begin{array}{l}\text { FGM, Joinvile, } \\
\text { SC, Brazil }\end{array}$} \\
\hline Condac 37 & Acid conditioner & $\begin{array}{l}\text { Low viscosity gel with phosphoric acid ( } 37 \text { wt. \% in } \\
\text { water), thickening agent and color pigments }\end{array}$ & \\
\hline $\begin{array}{l}\text { Variolink } \\
\text { Veneer }\end{array}$ & $\begin{array}{l}\text { Micro-filled, } \\
\text { light-curing luting } \\
\text { cement }\end{array}$ & $\begin{array}{l}\text { Urethane dimethacrylate, decamethylene } \\
\text { dimethacrylate, inorganic fillers, ytterbium trifluoride, } \\
\text { initiators, stabilizers, pigments and catalysts }\end{array}$ & \multirow{5}{*}{$\begin{array}{l}\text { Ivoclar } \\
\text { Vivadent; } \\
\text { Schaan, } \\
\text { Liechtenstein }\end{array}$} \\
\hline Monobond S & $\begin{array}{l}\text { Silane coupling } \\
\text { agent }\end{array}$ & $\begin{array}{l}\text { 1\% 3-methacryloxypropyltrimethoxy-silane, ethanol-/ } \\
\text { water-based solution }\end{array}$ & \\
\hline $\begin{array}{l}\text { Tetric } \\
\text { N-Bond }\end{array}$ & $\begin{array}{l}\text { Light-curing, } \\
\text { single-component } \\
\text { bonding agent }\end{array}$ & $\begin{array}{c}\text { Phosphoric acid acrylate, HEMA, Bis-GMA, urethane } \\
\text { dimethacrylate, ethanol, film-forming agent, catalysts } \\
\text { and stabilizers }\end{array}$ & \\
\hline Virtual & $\begin{array}{l}\text { Addition reaction } \\
\text { silicone impression } \\
\text { material }\end{array}$ & $\begin{array}{l}\text { Vinyl polysiloxane, methyl hydrogen siloxane, an } \\
\text { organoplatinic complex, silica and food dyes }\end{array}$ & \\
\hline $\begin{array}{l}\text { IPS e.max } \\
\text { Press }\end{array}$ & $\begin{array}{l}\text { Pressable lithium- } \\
\text { disilicate glass } \\
\text { ceramic }\end{array}$ & $\begin{array}{l}\text { Lithium disilicate, quartz, lithium dioxide, phosphorous } \\
\text { oxide, alumina, potassium oxide }\end{array}$ & \\
\hline
\end{tabular}

Figure 3. Manufacturers and chemical compositions of the materials used in the study 


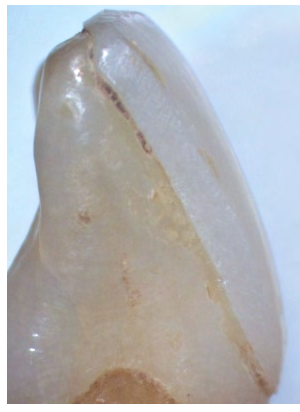

Figure 4. Criteria used for image evaluation and representative images of each score

\section{Results}

A significant difference was observed between the immersion conditions. Specimens stored in water presented less marginal staining, in comparison with specimens immersed in coffee $(p=0.000)$. Scores showing more intense pigmentation as 
Charlie and Delta were observed only in specimens immersed in coffee - mostly PE specimens - whereas Alfa and Beta scores were noticed for both groups in water immersion. The score Charlie presented tendency to be more equally distributed in all interfaces for IE and PE, while score delta, was more expressively present on PE in the mesial and distal interfaces. The absolute score distribution for each surface (cervical, mesial, distal and incisal) of PE and IE groups, immersed in water and coffee, is displayed in Table 1. A comparison of the marginal staining scores of IE and PE specimens immersed in water and coffee solutions is presented in Table 2. No statistical significance was found between IE and PE in water storage $(p=0.45)$. However, PE presented significantly more marginal staining in the coffee solution than IE $(p=0.01)$. Table 3 compares all surfaces marginal staining of IE and PE in the coffee immersion. The mesial surface presented significantly more marginal staining in PE group $(p=0.02)$.

Table 1. Surface score distribution for prepared and intact enamel restored with ceramic veneers, immersed in water and coffee solution

\begin{tabular}{|c|c|c|c|c|c|c|c|c|c|}
\hline \multirow{2}{*}{ Solution } & \multirow{2}{*}{ Surface Score } & \multicolumn{4}{|c|}{ Prepared enamel (PE) } & \multicolumn{4}{|c|}{ Intact enamel (IE) } \\
\hline & & $M$ & D & $\mathrm{C}$ & I & M & D & C & I \\
\hline \multirow{4}{*}{ Water } & Alfa & 0 & 0 & 0 & 3 & 2 & 0 & 1 & 2 \\
\hline & Bravo & 8 & 8 & 8 & 5 & 6 & 8 & 7 & 6 \\
\hline & Charlie & 0 & 0 & 0 & 0 & 0 & 0 & 0 & 0 \\
\hline & Delta & 0 & 0 & 0 & 0 & 0 & 0 & 0 & 0 \\
\hline \multirow{4}{*}{ Coffee } & Alfa & 0 & 0 & 0 & 0 & 0 & 0 & 0 & 0 \\
\hline & Bravo & 0 & 0 & 0 & 0 & 1 & 0 & 0 & 0 \\
\hline & Charlie & 4 & 6 & 8 & 7 & 7 & 8 & 8 & 7 \\
\hline & Delta & 4 & 2 & 0 & 1 & 0 & 0 & 0 & 1 \\
\hline
\end{tabular}

*Abbreviations: M - mesial, D - distal; C - cervical and I - incisal.

Table 2. Comparison between PE and IE in water and coffee solution - Mann-Whitney test

\begin{tabular}{|c|c|c|c|}
\hline \multirow{2}{*}{ Solution } & \multicolumn{2}{|c|}{ Median rank values } & \multirow[t]{2}{*}{ " $p$ " value } \\
\hline & Prepared enamel (PE) & Intact enamel (IE) & \\
\hline Water & 33.50 & 31.50 & 0.45 \\
\hline Coffee & 35.89 & 29.11 & 0.01 \\
\hline
\end{tabular}

Table 3. Score comparison between IE and PE specimens on each surface (mesial, distal, cervical and incisal) immersed in coffee solution - Mann-Whitney test $(n=8)$

\begin{tabular}{lcccc}
\hline Solution & Surface & IE & PE & "p" value \\
\hline \multirow{3}{*}{ Coffee } & Mesial & 86.00 & 50.00 & 0.020 \\
\cline { 2 - 4 } & Distal & 76.00 & 60.00 & 0.44 \\
\cline { 2 - 4 } & Cervical & 68.00 & 68.00 & 1.0 \\
\cline { 2 - 4 } & Incisal & 68.00 & 68.00 & 1.0 \\
\hline
\end{tabular}




\section{Discussion}

The present study demonstrated that both immersion solutions and enamel preparation influenced the marginal staining of the tooth/restoration interface. Marginal staining of the prepared group was significantly greater than the intact group, when immersed in coffee. Based on these results, the null hypothesis was rejected.

Extrinsic discoloration is associated with high intake of dietary colorants ${ }^{15}$, whereas intrinsic discoloration is influenced by physicochemical reactions of resin matrix monomers, size and content of inorganic particles, as well as the characteristics of the luting agents ${ }^{16}$. Therefore, esthetic failures are not due to the color change of the ceramic but as a result of the surface degradation from underlining cement and extrinsic color pigmentation ${ }^{17}$.

Coffee was chosen as an immersion solution, because of the high staining potential and because it is one of the most consumed beverages worldwide ${ }^{15}$. A period of 10 days of immersion corresponds to approximately one year of regular coffee consumption ${ }^{18}$. After the tenth day, the marginal finish line was visually perceptible on the prepared group. Projecting these findings to clinical practice, it may be assumed that marginal staining could be a clinical issue among coffee consumers after 1 year. Further studies with long-term clinical follow-up periods are required to confirm this assumption.

In the present study, the mesial surface showed significantly greater marginal staining of prepared specimens immersed in coffee. Such unexpected finding has no plausible explanation. The cervical area commonly presents increased staining and microleakage due to the lack of enamel in this region ${ }^{19}$. Conversely, Jha et al. ${ }^{20}$ (2013) found no difference in marginal adaptation between cervical, mesial, distal and incisal margins, in veneers fabricated by both the heat pressing and the refractory die techniques.

Restoration of lower incisors with ceramic veneers is considered a challenging task due to the limited dimensions and small amount of enamel available for bonding ${ }^{21}$. However, a retrospective study, showed similar success rates on both mandibular and maxillary incisors after 36 months ${ }^{22}$. The preparation design and enamel margins were carefully examined prior to cementation, however, the presence of thin enamel in the cervical area of the lower incisors often creates undetected dentine exposure, which may explain the increased marginal staining of the prepared specimens ${ }^{19}$.

Controversial results regarding the bond strength of ground and unground enamel can be observed. Some studies found no difference between prepared and intact enamel, whereas others consider that unprepared enamel yields lower bond strength values $^{23,24}$. In the present study, the quality of the adhesion was not evaluated, however, the least amount and intensity of staining observed on the intact surfaces suggests that the adhesion was not affected by the lack of preparation. Research involving this issue should be addressed to elucidate this hypothesis.

Lithium disilicate reinforced ceramic was used in the fabrication of the veneers because of the excellent esthetic characteristics, biocompatibility and adhesive properties of these ceramics ${ }^{25}$. In addition, the high strength in small thickness enables the indication of minimally invasive procedures ${ }^{12}$. In this study, $0.3 \mathrm{~mm}$ and $0.5 \mathrm{~mm}$-thick high translucency BL 3 shade ingots were used. The ceramic veneers were cemented 
with resin cement shade LV 1, the color shade and translucency of the cement may have affected the perception of marginal staining of specimens immersed in coffee. Resin cements with opaque and more saturated shades, as well as ceramic veneers with reduced thickness, may affect the overall color change in translucent 0.5 mm-thick veneers ${ }^{15,26}$.

Water may induce aging of resin composites and subsequent staining ${ }^{27}$. It was possible to state that the specimens stored in water did not exhibit intense staining. The majority of the pigmentation scores were associated with no staining (Alfa score) or slight discontinued grayish staining with predominance of no staining (Bravo score), probably not compromising the esthetic results. The composition of the light-cured cement used in this study could explain this slight pigmentation, since TEGDMA may be associated with water intake and staining ${ }^{8},{ }^{18}$. Artificial aging and thermocycling were not conducted. If applied, they would probably have contributed to more intense staining in either groups. Apart from that, the microscopic images could have overestimated the findings.

This experimental study confirms that the enamel preparation was associated with greater marginal staining, thus suggesting that maintaining unprepared intact enamel contributes to long-term esthetic outcomes. Moreover, marginal staining may be influenced by different factors that should be studied individually. Ceramic veneers placed on unprepared enamel are still a recent conservative trend, and long-term clinical trials are needed to evaluate if conservation of tooth structures will meet expectations and lead to high success rates.

In conclusion, marginal staining was affected by the enamel preparation. Cementation of ultra-thin ceramic veneers to intact enamel provides a dental restoration interfaces with less marginal staining.

\section{Clinical relevance}

Ultra-thin veneers with no enamel preparation preserves tooth integrity and reduces marginal staining.

\section{References}

1. Beier US, Kapferer I, Burtscher D, Dumfahrt H. Clinical performance of porcelain laminate veneers for up to 20 years. Int J Prosthodont. 2012 Jan-Feb;25(1):79-85.

2. Vanliołlu BA, Kulak-Özkan Y. Minimally invasive veneers: current state of the art. Clin Cosmet Investig Dent. 2014 Nov;6:101-7. doi: 10.2147/CCIDE.S53209.

3. Layton DM, Clarke M. A systematic review and meta-analysis of the survival of non-feldspathic porcelain veneers over 5 and 10 years. Int J Prosthodont. 2013;26(2):111-24. doi: 10.11607/ijp.3202.

4. Ge C, Green CC, Sederstrom DA, McLaren EA, Chalfant JA, White SN. Effect of tooth substrate and porcelain thickness on porcelain veneer failure loads in vitro. J Prosthet Dent. 2018 Jul;120(1):85-91. doi: 10.1016/j.prosdent.2017.10.018.

5. Aboushelib MN, Elmahy WA, Ghazy MH. Internal adaptation, marginal accuracy and microleakage of a pressable versus a machinable ceramic laminate veneers. J Dent. 2012 Aug;40(8):670-7. doi: 10.1016/j.jdent.2012.04.019. 
6. D'Arcangelo C, De Angelis F, Vadini M, D'Amario M. Clinical evaluation on porcelain laminate veneers bonded with light-cured composite: results up to 7 years. Clin Oral Investig. 2012 Aug;16(4):1071-9. doi: 10.1007/s00784-011-0593-0.

7. Marchionatti AME, Wandscher VF, May MM, Bottino MA, May LG. Color stability of ceramic laminate veneers cemented with light-polymerizing and dual-polymerizing luting agent: A split-mouth randomized clinical trial. J Prosthet Dent. 2017 Nov;118(5):604-10. doi: 10.1016/j.prosdent.2016.11.013.

8. Archegas LRP, Freire A, Vieira S, Caldas DBDM, Souza EM. Colour stability and opacity of resin cements and flowable composites for ceramic veneer luting after accelerated ageing. J Dent. 2011 Nov;39(11):804-10. doi: 10.1016/j.jdent.2011.08.013.

9. Myers ML, Caughman WF, Rueggeberg FA. Effect of restoration composition, shade, and thickness on the cure of a photoactivated resin cement. J Prosthodont. 1994 Sep;3(3):149-57. doi: 10.1111/j.1532-849x.1994.tb00146.x.

10. Gurel G, Sesma N, Calamita MA, Coachman C, Morimoto S. Influence of enamel preservation on failures rates of porcelain laminate veneers. Int J Periodontics Restor Dent. 2013 Jan-Feb;33(1):31-9. doi: $10.11607 /$ prd. 1488

11. Granell-Ruiz M, Fons-Font A, Labaig-Rueda C, Martinez-Gonzalez A, Roman-Rodriguez J, Sola-Ruiz M. A clinical longitudinal study 323 porcelain laminate veneers. Period of study from 3 to 11 years. Med Oral Patol Oral y Cir Bucal. 2010 May;15(3):e531-7. doi:10.4317/medoral.15.e531.

12. Ma L, Guess PC, Zhang Y. Load-bearing properties of minimal-invasive monolithic lithium disilicate and zirconia occlusal onlays: finite element and theoretical analyses. Dent Mater. 2013 Jul;29(7):742-51. doi: 10.1016/j.dental.2013.04.004

13. Kilinc E, Antonson SA, Hardigan PC, Kesercioglu A. Resin cement color stability and its influence on the final shade of all-ceramics. J Dent. 2011 Jul;39 Suppl 1:e30-6. doi: 10.1016/j.jdent.2011.01.005.

14. Çömlekoğlu E, Önem E, Dündar Çömlekoğlu M, Baksi BG, Mert A. Detection of artificial demineralization bordering different types of laminate veneers using visual inspection and storage phosphor radiography. 2013 Jul;17(6):1507-14. doi: 10.1007/s00784-012-0847-5.

15. Turgut S, Bagis B. Colour stability of laminate veneers: an in vitro study. J Dent. 2011 Dec;39 Suppl 3:e57-64. doi: 10.1016/j.jdent.2011.11.006.

16. Türkün LS, Türkün M. Effect of bleaching and repolishing procedures on coffee and tea stain removal from three anterior composite veneering materials. J Esthet Restor Dent. 2004;16(5):290-301; discussion 301-2. doi: 10.1111/j.1708-8240.2004.tb00056.x.

17. dos Santos DM, da Silva EVF, Watanabe D, Bitencourt SB, Guiotti AM, Goiato MC. Effect of different acidic solutions on the optical behavior of lithium disilicate ceramics. J Prosthet Dent. 2017 Sep;118(3):430-6. doi: 10.1016/j.prosdent.2016.10.023.

18. Shiozawa M, Takahashi $\mathrm{H}$, Asakawa $\mathrm{Y}$, Iwasaki N. Color stability of adhesive resin cements after immersion in coffee. Clin Oral Investig. 2015 Mar;19(2):309-17. doi: 10.1007/s00784-014-1272-8.

19. Öztürk E, Bolay Ş, Hickel R, Ilie N. Shear bond strength of porcelain laminate veneers to enamel, dentine and enamel-dentine complex bonded with different adhesive luting systems. J Dent. 2013 Feb;41(2):97-105. doi: 10.1016/j.jdent.2012.04.005.

20. Jha R, Jain V, Das TK, Shah N, Pruthi G. Comparison of marginal fidelity and surface roughness of porcelain veneers fabricated by refractory die and pressing techniques. J Prosthodont. 2013 Aug;22(6):439-44. doi: 10.1111/jopr.12032.

21. Walter RD, Raigrodski AJ. Critical Appraisal: clinical considerations for restoring mandibular incisors with porcelain laminate veneers. J Esthet Restor Dent. 2008;20(4):276-277. doi:10.1111/j.1708-8240.2008.00192.x 
22. Rinke S, Lange K, Ziebolz D. Retrospective study of extensive heat-pressed ceramic veneers after 36 months. J Esthet Restor Dent. 2013 Feb;25(1):42-52. doi: 10.1111/jerd.12000.

23. Perdigão J, Gomes G, Duarte S, Lopes MM. Enamel bond strengths of pairs of adhesives from the same manufacturer. Oper Dent. 2005 Jul-Aug;30(4):492-9.

24. Yazici AR, Yildirim Z, Ertan A, Ozgunaltay G, Dayangac B, Sibel A Antonson SA, et al. Bond strength of one-step self-etch adhesives and their predecessors to ground versus unground enamel. Eur J Dent. 2012 Jul;6(3):280-6. doi: 10.1055/s-0039-1698962.

25. Kesrak P, Leevailoj C. Surface hardness of resin cement polymerized under different ceramic materials. Int J Dent. 2012;2012:317509. doi: 10.1155/2012/317509.

26. Turgut S, Bagis B. Effect of resin cement and ceramic thickness on final color of laminate veneers: an in vitro study. J Prosthet Dent. 2013 Mar;109(3):179-86. doi: 10.1016/S0022-3913(13)60039-6.

27. Vichi A, Ferrari M, Davidson CL. Color and opacity variations in three different resin-based composite products after water aging. Dent Mater. 2004 Jul;20(6):530-4. doi: 10.1016/j.dental.2002.11.001. 